\title{
Integration of Field Data and Online Satellite Images to Map Urban Change Pattern From 2003 to 2013, Case Study: Darbandikhan, Kurdistan Region, Iraq
}

\author{
Iraj Rahimi $^{1^{*}}$, Salim Neimat Azeez ${ }^{1}$, Imran Hasan Ahmad ${ }^{1}$ \\ ${ }^{I}$ Surveying Dept, Darbandikhan Technical Institute, Sulaimani Polytechnic University, Darbandikhan- Sulaimani, Kurdistan Region, Iraq
}

Received 25 September 2021; revised 30 November 2021;

accepted 12 December 2021; available online 04 January 2021

doi:10.24271/psr.37

\begin{abstract}
Remote Sensing accompanied with GIS is a powerful way of mapping land-use/cover change at different spatial and temporal resolutions. This study aims to map the urban land use change of the small city of Darbandikhan, in the west of Kurdistan Region-Iraq using Google Earth time series images, as well as, field statistical data, from 2003 to 2013 which is considered as the most prosperous economic period within the study area. Results showed that the city has extended by 2.7 times, from almost $1.9 \mathrm{~km}^{2}$ in 2003 to $5.3 \mathrm{~km}^{2}$ in 2013, mainly to the North and West of the city considering the potentials of the area. During that period residents have doubled mainly because of the rural movement toward urban areas as the result of economic flourishment caused by the economic evolvement in 2003. Also, the developed map has revealed the fact that the distribution of the facilities, except for schools, is not organized. It has been located in such a way around the city center exclusively. The developed map, also revealed, that the distribution of facilities, except schools, not well distributed all over the town and mainly maintain around the city center. Furthermore, the roads, as showed on the map, are mostly $(90 \%)$ less than $15 \mathrm{~m}$ wide which rarely met the transportation demands of the city.
\end{abstract}

(c) 2022 Production by the University of Garmian. This is an open access article under the LICENSE

https://creativecommons.org/licenses/by-nc/4.0/

Keywords: Urban Change pattern, Darbandikhan, RS/GIS, Google Earth, Land Use/Cover.

\section{Introduction}

The expansion of residential area and urbanization development have an inevitable impact on the behavior of the Erath cycles ${ }^{[1]}$. On the other hands, the environmental situation strongly affects people movement; they have a mutual interaction ${ }^{[2]}$. It's also proven that change in Land Use and Land Cover (LULC) is considered as heart of the sustainable development debate and it considered as one of the most important factors of the global-scaled environmental transformations ${ }^{[3]}$. There are many contributing factors, both natural-based and human-based, which may result in changes in LULC ${ }^{[4]}$. Many formal reports and researches show that human-based activities are the main driving force that change the land covers, as well as, climate changes ${ }^{[4,5]}$. These changes are proved to have substantially changed about $80 \%$ of the Earth's land area over the recent centuries ${ }^{[6]}$. Urbanization is most likely accompanied with the changes in economic social variables, therefore, many researches

* Corresponding author

E-mail address: iraj.amin@spu.edu.iq (Instructor).

Peer-reviewed under the responsibility of the University of Garmian. offer those urban authorities should think of optimum strategies to monitor the way land is now used, so that, they will be able to comprehensively plan and make the best decision how urban areas may change ${ }^{[7]}$. The accelerated change of LULC, specifically in developing countries, are accompanied with uncontrolled urban sprawling and land degradation, which will result in many unavoidable environment catastrophes ${ }^{[8]}$. In addition, the LULC change will change biotic diversity, soil quality, etc. ${ }^{[9]}$. Therefore, it seems quite necessary to monitor and detect the changes of LULC, to minimize the urbanization side effects on the ecosystem and to reach sustainable land use/ cover planning $[10,11]$. As it has been discussed in more details, migration phenomenon depends on several factors, including social characteristics, as well as, political and economic condition [12]. The movement of rural residents to the margin of cities has always been considered a criterion to assess the economic condition of urban ${ }^{[13]}$. In 1995, more than 25 million people migrated as a result of environmental changes. This number is estimated to rise by 200 million in ${ }^{[13]}$. In Iraq, in Kurdistan Region especially, during recent decades, a salient group of Kurdish people has migrated to urban areas from rural areas primarily due to the war between Iran and Iraq which lasted about 
eight years. Furthermore, the concentration of facilities in urban areas, as well as, the conversion of lifestyle has resulted in an uncontrollable urban growth phenomenon. For Iraqis, totally considering, and for Kurdish people in this country, particularly, the migration, both internal and international, has always been considered as a challenge ${ }^{[14,15]}$.

The issue of urbanization and its possible consequences is a manifold issue. There are plenty of scholars scrutinizing the interaction between urban growth and its environmental consequences. The modern technologies such as satellite data and geoscience data management and methods has opened a new era for researches, both ecological and geographical, to look upon the Earth much easier as it was before considering the costs and time needed to manipulate a field study ${ }^{[16]}$. Flexibility to provide views, repetitive coverage over a single area and real time and near real time data acquisition, have let Remote Sensing (RS) data and techniques to be extremely useful in environmental and urban management ${ }^{[17]}$. Satellite imageries, would let engineers to create various land cover/use thematic maps accurately. It also helps in manipulating the spatial data which are considered fundamental for mapping and visualizing land use conversion ${ }^{[17]}$. Accordingly, satellite remote sensing techniques, integrated with Geographic Information System (GIS), regarded as powerful way of assessing and mapping land-use/cover change at different spatial and temporal resolution ${ }^{[18]}$. It also offers lower costs and time than those done using the traditional models ${ }^{[18]}$. GIS is a powerful decision support system, that can be used urban planning project. GIS is widely used in modeling of urban expansion, as well as, environmental modelling. Furthermore, by determining distances of current urban growth areas from previously built town infrastructures, GIS enables us to map spatial patterns of urban changes ${ }^{[19,20]}$. Simply, the integration of RS/GIS would let urban planner to analysis of two recorded aerial or satellite images of an area which are registered at two different dates and then they will be able to assess the changes that is have taken places in the area between the two dates ${ }^{[21,22]}$. In other words, these abilities will let them to monitor and process the variation in the state of the phenomenon among as urban area. Either like many countries all over the world, In Iraq, also, RS/GIS have been used as a reliable and modern technology to monitor land cover/use changes ${ }^{[23,24]}$. A study was conducted, in Karbala, to determine the land cover changes between 1976 and 2011 Governorate by using an integrated approach of remote sensing data and GIS applications to assess the spatial and temporal changes ${ }^{[25]}$. Furthermore, ${ }^{[26]}$ used Landsta TM and ETM to map urban area around the Al-Nasiriyah city between the year 1989 and 2,014 in order to predict its probable future growth by use of remote sensing and GIS techniques.

Likewise, an investigation has been carried out to assess the effect of land use changes on Land Surface Temperature (LST) depends on data from three Landsat images in Dihok, Kurdistan Region, Iraq ${ }^{[27]}$. In order to model the future changes of land use/cover for the Erbil governorate in the Kurdistan region of Iraq (KRI), ${ }^{[28]}$ used the synergy Cellular Automata (CA)-Markov model using three consecutive-year Landsat imagery (1988, 2002, and 2017). Maximum likelihood supervised classification and postclassification on Landsat images acquired in 1987 and 2001, also, have been used to detect change to map land cover changes in the Northwestern coast of Egypt ${ }^{[29]}$. The aim of this study is to map urban change pattern of the small city of Darbandikhan, located in Sulaymaniyah Province, in the west of Kurdistan Region-Iraq, from 2003 to 2013, using online accessible satellite image database, Google Image, and field data.

\section{Study area}

This research is dealing with Darbandikhan city which is located in Sulaymaniyah Province, between $\left(45^{\circ} 39^{\prime} 6.12^{\prime \prime} \mathrm{E}, 35^{\circ}\right.$ $\left.7^{\prime} 24.74^{\prime \prime N}\right)$ as the Northeast, and $\left(45^{\circ} 41^{\prime} 32.88^{\prime \prime} \mathrm{E}, 35^{\circ} 6^{\prime} 4.62^{\prime \prime} \mathrm{N}\right)$ as the Southwest, respectively, at the Southwest of Kurdistan Region which is governed Kurdistan Region Government (KRG), Iraq (Figure 1). Based on official data, Darbandikhan was resided by almost 42500 residents in 2013. A neighbor to many natural attractions, Sirwan River, and the dam which has been built on Sirwan river in 1961, accompanied with moderate weather, has made this city important ecologically and socioeconomically. Furthermore, since Darbandikhan is located on one of the major ways of exporting oil from KRG to Iran, and importing from Iran to KRG, so it could be easily concluded that the city is located in a strategic location. In addition, passengers, from Sulaymaniyah and Halabja provinces, mostly pass this way to go to Baghdad, the capital of Iraq. These characteristics, altogether, has made this city as an attractive city to call a large number of people to visit it and, also, has resulted in migration of rural residents to this city during recent decades.

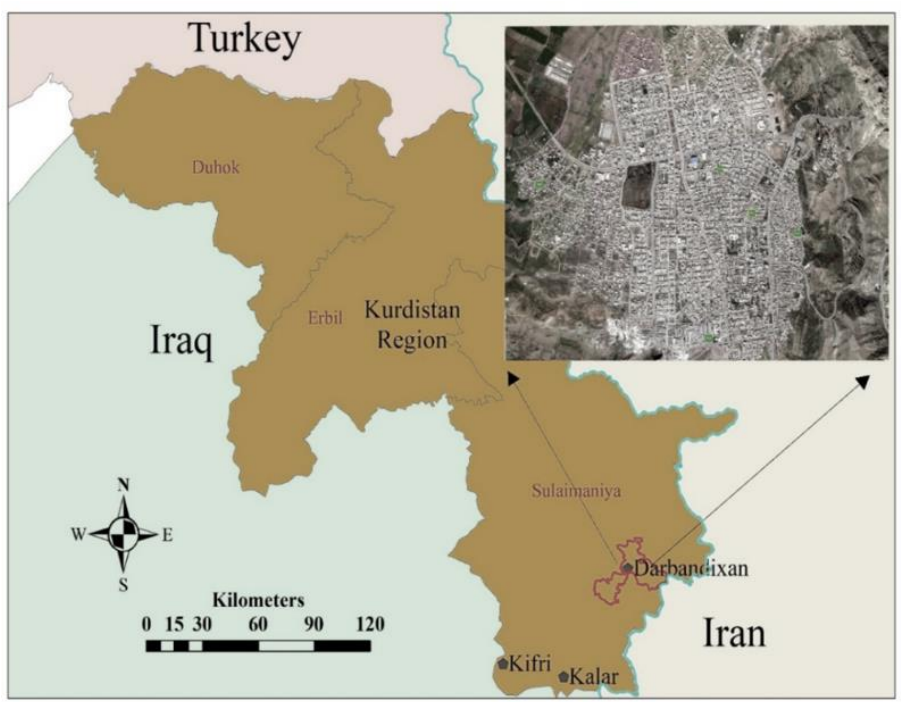

Figure 1: The location of study area, at the Southwest of KRG, East of Iraq.

\section{Materials and Methodology}

Two sets of data have been used in this research. The first dataset was satellite derived images which have been provided by Google and Being companies. Universal Image Downloader was used to download the images which is owned and developed by allmapsoft website ${ }^{[30]}$. This software can be easily used to download real color satellite images (RGB bands) provided by official Google Earth websites which is free of charge and also one of the most easily access data set, and carrying out a time series analysis for small land areas. Since this study focuses on geometric aspects rather than creating thematic and land cover maps, so the panchromatic images provided by Google Earth 
engine is considered enough to meet our objectives ${ }^{[31]}$. Many studies have used Google Earth images as a reliable data to map urban land use/cover change ${ }^{[32,33]}$. Two panchromatic image sets were downloaded based on the turning point realms. First taken in 2003 which the Iraqi previous regime, Baas, collapsed and new economic condition started. Started from 2003, an unexampled population growth accompanied unsupervised developmental activities have led to substandard and nonstandard urbanization, with insufficient infrastructure facilities. The second images set belongs to 2013, which started to experience a noticeable decline of economic abundance, which resulted in the recent economic challenges that KRG have been facing. Reported by Iraqi Economic Network, from 2003 to 2013 Iraq has expressed the most prosperous economic condition until (Figure 2) ${ }^{[34]}$.

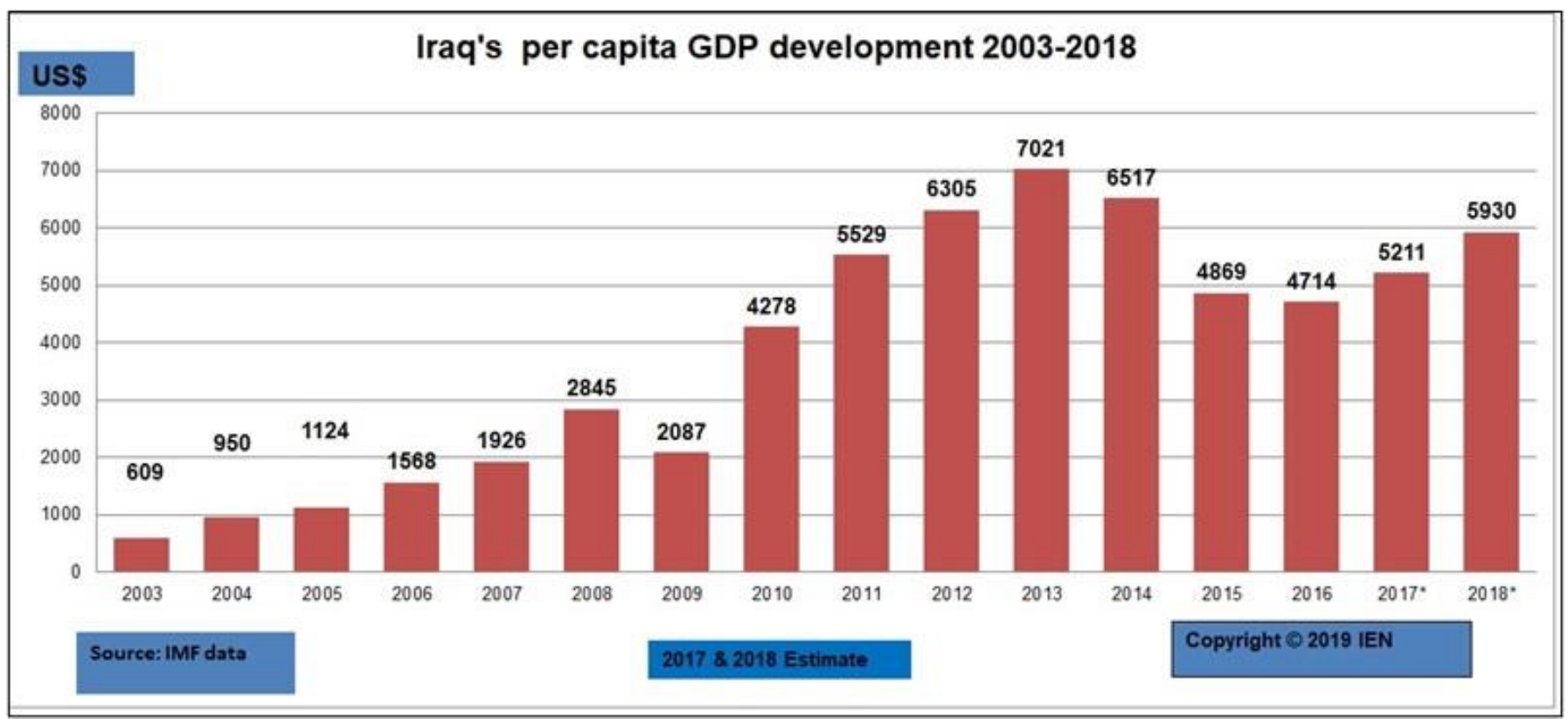

Figure 2: Gross domestic product (GDP), from 2003 to 2018. Reported by Iraqi Economists Network (IEN). GDP is the standard measure of the value added created through the production of goods and services in a country during different period.

The second data set includes the field data covering the location of urban units and elements (schools, sanitary centers, mosques, administrative sites, public and academic institutions etc.), as well as, some basic statistics like population and population variation from 2003 to 2013. First of all, the georeferenced satellite images were opened by ArcGIS. Then the location of schools, administrative sites, mosques, public institution, industrial district, academic institutions, city center, and sanitary center on the satellite image taken in 2013, were visually determined on the image. This process accompanied with field observation to verify the urban elements on the map. Each one, then converted into a shapefile in ArcGIS (Figure 3).

In order to find out the area of the urban area in 2003 and 2013, and its growth during this period, the boundary of the Darbandikhan town was extracted from the satellite image and converted to a layer separately (Figure4). The calculations revealed that he area of Darbandikhan has widen by 2.7 times from $1,942,000 \mathrm{~m}^{2}$ in 2003 , to meet5,353,400 $\mathrm{m}^{2}$ in 2013 (Table $1)$.

Table 1: The area of the Darbandikhan town.

\begin{tabular}{|l|l|l|}
\hline Year & Area $\left(\mathbf{m}^{\mathbf{2}}\right)$ & Rate of growth \\
\hline $\mathbf{2 0 0 3}$ & $1,942,000$ & \multirow{2}{2}{$275 \%$ (2.7 times) } \\
\hline $\mathbf{2 0 1 3}$ & $5,353,400$ & \\
\hline
\end{tabular}

The population of Darbandikhan town as well as reported by periodical report of Sulaimaniyah Statistical Office has almost been doubled during the studied period, from 2003 to 2013 (Table2) ${ }^{[35]}$. To calculate the rate of growth the equation below was used, where $\mathrm{N}_{1}$ is the population for the start of the period, and $\mathrm{N}_{2}$ is the end of the period.

$$
\text { rate of growth }=\frac{\mathrm{N} 2-\mathrm{N} 1}{\mathrm{~N} 1}
$$

Accordingly, the rate of growth from 2003 to 2013 is almost $100 \%$, while it was about $51 \%$ from 1977 to 1987 , and $36 \%$ from 1987 to 2003.

Table 2: Population of Darbandikhan and rate of urban population growth ${ }^{[35]}$.

\begin{tabular}{|c|c|c|}
\hline Year & Urban Population & Rate of Growth \\
\hline $\mathbf{1 9 7 7}$ & 10360 & \\
\hline $\mathbf{1 9 8 7}$ & 15678 & $51 \%(1997$ to 1987$)$ \\
\hline $\mathbf{2 0 0 3}$ & 21373 & $36 \%(1987$ to 2003$)$ \\
\hline $\mathbf{2 0 1 3}$ & 42625 & Almost $100 \%(2003$ to \\
\hline
\end{tabular}




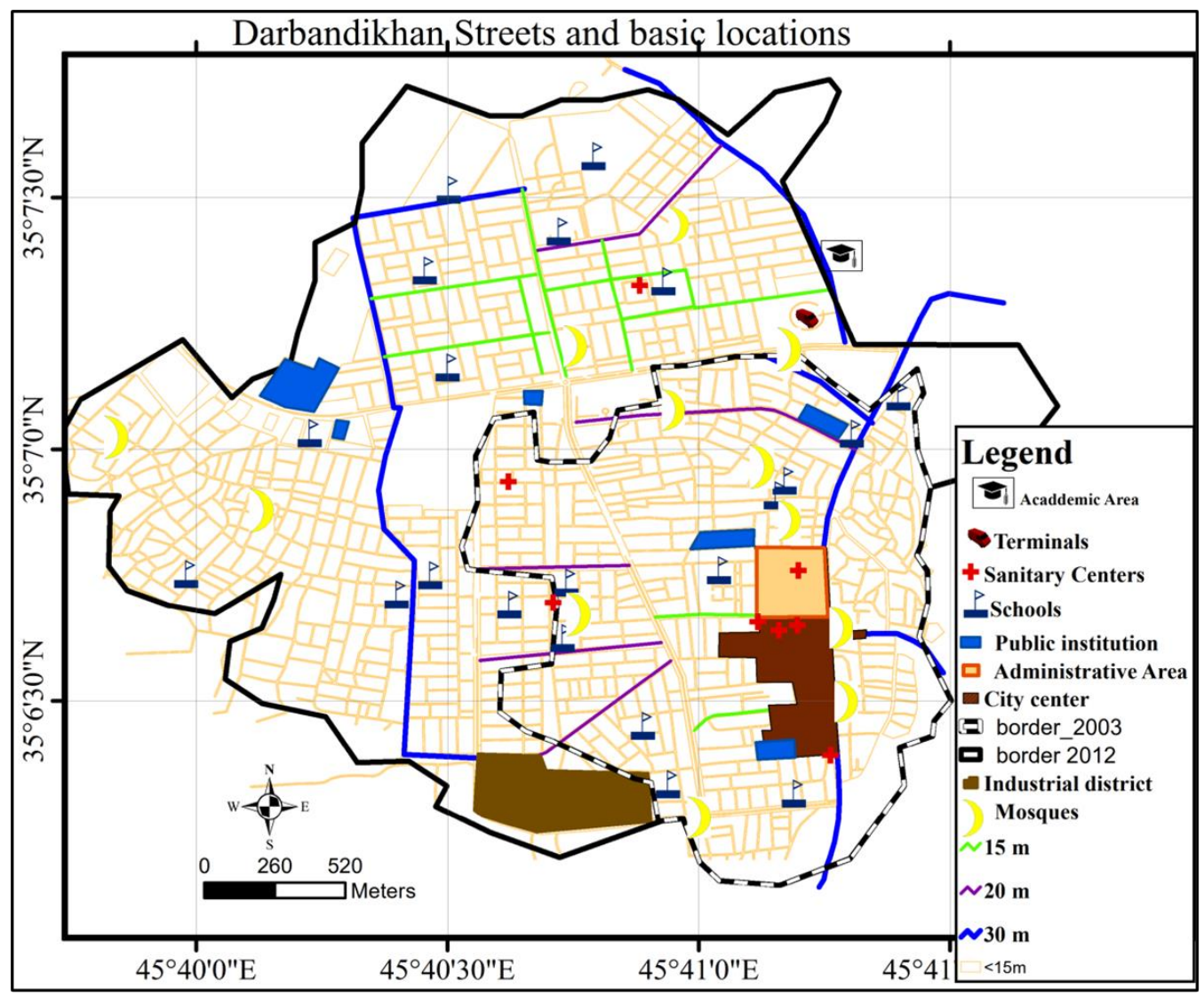

Figure 3: Urban growth sprawl map. Most of urban facilities sustained in the previous border of the town (2003's border). From 2003 to 2013 most of the facilities have maintained around the city center which have resulted in not well distribution of facilities and concentration of bad traffic situation inside the city center.

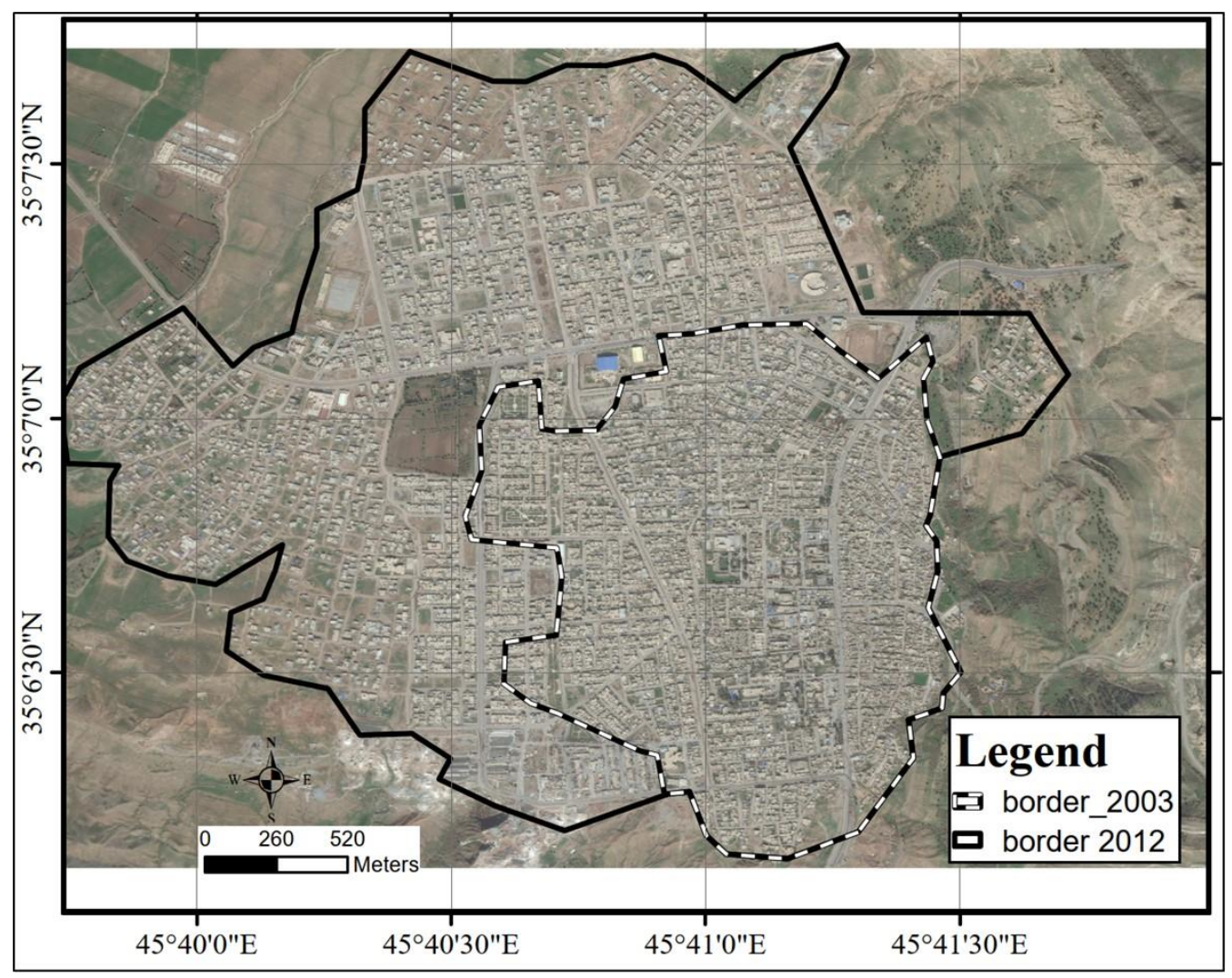

Figure 4: Darbandikhan's area in 2003, and in 2013. 


\section{Results and discussion}

There are two result sets, map-based and statistical- based. The map-based result describes spatial parameters and the statisticalbased result shows population changes. As seen in Figure (4), Darbandikhan town has sprawl, from 2003 to 2013, mostly to the North and the West of the area it covers in 2003. The directions of growth, the north and the west, have actually had the most potential to sprawl, as the topographic characteristic of these tow direction, mostly flat and easily accessible, are more convenient than another direction. The rate of growth reveals a noticeable change in this period. In 2013 the covered area of the town is 2.7 times greater than 2003. After the invasion of Iraq in 2003, the situation economy of Kurdistan boomed due to new politicaleconomic situation in the region. The KRG administrative was wealthy enough to offer plenty of affordable mortgages to the inhabitants and a free parcel of land to build a house which resulted in urban expansion in KR. As the result, as seen, the research intended period, 2003 to 2013, the maximum rate of population change has taken place in Darbandikhan city (about
$100 \%$ ), compared to other periods (table 2). It also shows, the most movement, form rural area to urban area, has taken placed during this period, too, as there is a minimum difference between the population of the city and district in 2013 and more than $91 \%$ of the whole district are living in the city (less than 4500 people remained in rural area), while in 2003 this difference was quite bigger, since only about $70 \%$ of the whole residents are living in the city (Table 3) the rest, (more than 30\%) are still living in rural areas). From 2013 to 2018, the rate of change in urban residents seemed to be quite slower than before.

Although the population has also increased but it only doubled (Table 2), obviously, the increase in terms of population and occupied area are not following the same pattern. This nonconsistency might be originated from the unplanned urban policies. Additionally, the dominant architectural style, inclination to build big hoses, may be considered as another reason. Totally, based on the official reports, immigration from a rural area to urban area is considered as the main factor to justify the growth population.

Table 3: The percent of town population in Darbandikhan district ${ }^{[35]}$.

\begin{tabular}{|c|c|c|c|c|}
\hline Year & Urban Pop. & District Pop. & $\begin{array}{c}\text { Rural Pop } \\
\text { Distrivt Pop - Urban Pop }\end{array}$ & $\begin{array}{c}\text { Urban population (\%) } \\
\frac{\text { urban pop }}{\text { distric pop }} * 100\end{array}$ \\
\hline 1977 & 10360 & 21835 & 11475 & $47 \%$ \\
\hline 1987 & 15678 & 36462 & 20784 & $33 \%$ \\
\hline 2003 & 21373 & 30261 & 8888 & $70 \%$ \\
\hline 2013 & 42625 & 47041 & 4416 & $91 \%$ \\
\hline 2018 & 45500 & $\ldots \ldots$ & & \\
\hline
\end{tabular}

According to (Figure 3), except the schools, which shows the location of all urban items, distribution of almost all of urban structure has rarely followed the growth of the town. As observed, most of facilities, sanitary centers, public institutions and marketing centers, have maintained around the city center which have resulted in not well distribution of facilities and consequently concentration of bad traffic situation inside the city center. From 2003 to 2013, almost all administrative offices have not moved away, but the Court and the Polytechnic Institute of Darbandikhan, which can be regarded as source of heavy traffic, too. The results, also, show that the majority of the streets are less than $15 \mathrm{~m}$ wide (Table (4)) which hardly meet the traffic needs of the city which naturally have results in lack of parking space within the town. It also reveals that the traffic density of the roads has not been considered and most of the road follows almost the same design, not regarding the possible traffic load. The mostly narrow road network of the Darbandikhan, also, does not let urban manager to rethink of new design to reconstruct road network or add cycle lines to road network.

Table 4: Types and percent of streets of Darbandikhan. The majority of roads are $<15$ wide.

\begin{tabular}{|c|c|}
\hline Road classes & percent \\
\hline $30 \mathrm{~m}$ & $5 \%$ \\
\hline $20 \mathrm{~m}$ & $3 \%$ \\
\hline $15 \mathrm{~m}$ & $2 \%$ \\
\hline$<15 \mathrm{~m}$ & $90 \%$ \\
\hline
\end{tabular}

\begin{tabular}{|l|}
\hline Description \\
\hline Major roads, a network of 6 streets \\
\hline Minor roads, Distributed between major roads \\
\hline Minor roads, involves 4 roads between majors \\
\hline Compose the majority of city transport network \\
\hline
\end{tabular}

\section{Conclusion and Recommendations}

Based on the map (Figure 4), we can find that the land policy is segregated. The concept of mix use is marginalized. The access and collector roads do not function as they are. The $30 \mathrm{~m}$ streets are semi-circle and they should have redesigned and getting wider when the diameter from the city center increases. Furthermore, it is possible to locate all governmental service building in the city center with providing coherent car parking policy and reliable public transport. Although, some governmental service buildings have been relocated to some other neighborhoods which lead the inhabitants to be car dependent, but the schools are within a walkable distance and comply with the Iraqi Standard which is $300 \mathrm{~m}$. The other service building and playfield, play sport, cultural center does not fulfill the needs of the inhabitants according to the Iraqi standard which is $800 \mathrm{~m}$.

We are now in 2021, in the next studies we will be offering a map to show urban changes from 2013 to 20201 and find out how the city pattern has been changed. To scrutinize even deeper into modeling all urban details in the study area, as we as, getting further information about how urban growth and residents' interplay, it is proposed to do a cooperative study to model 
socioeconomic aspect of migration. In addition, it will be quite helpful to use time series satellite images, as well as, high resolution images to do change detection. It can also be a good idea to use multispectral satellite images to modeling land cover changes during these periods.

\section{Conflict of interests}

None.

\section{References}

1. Burian, S.J. and Shepherd, J.M., Effect of urbanization on the diurnal rainfall pattern in Houston. Hydrol. Process., v.19, pp.10891103. https://doi.org/10.1002/hyp.5647(2005)

2. Miller, R. B., \& Small, C. Cities from space: potential applications of remote sensing in urban environmental research and policy," environmental Science \& Policy, V.6(2), pp.129-137. doi:10.1016/S1462-9011(03)00002-9 (2003)

3. Hegazy, I.R.; Kaloop, M.R. Monitoring urban growth and land use change detection with GIS and remote sensing techniques in Daqahlia governorate. Egypt International Journal of Sustainable Built Environment, V.4, pp.117-124, doi: doi.org/10.1016/j.ijsbe.2015.02.005 (2015)

4. Rahimi, I., Azeez, S. N., \& Ahmed, I. H. Mapping forest-fre potentiality using remote sensing and GIS, case study: Kurdistan Region-Iraq. In A. Al-Quraishi\& A. M. Negm (Eds.), Environmental remote sensing and GIS in Iraq (pp. 499-513). New York: Springer. Doi: dx.doi.org/10.1007/978-3-030-21344-2_20 (2020)

5. Alves, D., Skole D. Characterizing land cover dynamics using multi-temporal imagery. International Journal of Remote Sensing, V.17 (4). pp.835-839.Doi: doi.org/10.1080/01431169608949049 (1996)

6. Vitosek, P.M., Mooney, H.A., LuBcheneo, J., Melhao, J.M. Human Domination of Earth's Ecosystems," Science, V.277, pp.494-499. (1997)

7. Sivakumar V. URBAN MAPPING AND GROWTH PREDICTION USING REMOTESENSING AND GISTECHNIQUES, PUNE, INDIA. The International Archives of the Photogrammetry, Remote Sensing and Spatial Information Sciences, V.8, pp. 967-970. Doi: 10.5194/isprsarchives-XL-8-967-2014(2014)

8. Sankhala, S., Singh, B. (2014). Evaluation of urban sprawl and land use land cover change using remote sensing and GIS techniques: a case study of Jaipur City, India. International Journal of Emerging Technology and Advanced Engineering. Eng. V.4 (1), pp.66-72, (2014)

9. Steffen, W.L., Walker, B.H., Ingram., J.S., Koch, G.W.“Global Change and TerrestrialEcosystems: The Operational Plan IGBP Report” International GeosphereBiosphere Program, Stockholm, No.21, pp: 53-65. (1997)

10. Muttitanon, W., Tripathi, N. Land use/cover changes in the coastal zone of Bay Don Bay, Tailand using Landsat 5 TM data. International Journal of Remote Sensing, V.26 (11). pp. 2311-2323.Doi: doi.org/10.1080/0143116051233132666(2005)

11. Boano, C (2008). FMO research guide on climate change and displacement, Forced Migration Online. PP.18-21.

12. Black, R., Kniveton, D., \& Schmidt-Verkerk, K. Migration and climate change. Environment and Planning, V.43(2). pp. 431-450, (2011)

13. Myers, N., \& Kent, J. Environmental exodus: an emergent crisis in the global arena,". Climate Institute. (1995)

14. Sirkeci, I. War in Iraq: Environment of insecurity and intrnational migration. International Migration. V.43(4), pp.197-214.Doi: dx.doi.org/10.1111/j.14682435.2005. 00338.x(2005)

15. Black, G. (1993). Genocide in Iraq: The Anfal campaign against the Kurds," Human Rights Watch.

16. Kumar, S. \&Arivazhagan, Sundaram\&Rangarajan, N. Remote Sensing and GIS Applications in Environmental Sciences - A Review. J. Environ. Nanotechnol. Doi: 2. 92-101. 10.13074/jent.2013.06.132025 (2013)

17. Mukherjee, S. Land use maps for conservation of ecosystems,". Geographic Review of India, V.3, pp.23-28. (1987)
18. El-Raey, M., Nasr, S., El-Hattab, M., Frihy, O. Change detection of Rosetta Promontory over the last forty years. International Journal of Remote Sensing, V.16, pp. 825-834.Doi: doi.org/10.1080/01431169508954446(1995)

19. Gar-On Yeh, A., Xia, L. Measurement and monitoring of urban sprawl in a rapidly growing region using entropy," Photogrammetry Engineering and Remote Sen. V.67 (1), pp. 83-90. (2001)

20. Salar, Sarkawt. (2017). Urban Geomorphology of Darbandikhan District Using GIS \& RS Iraqi Kurdistan Region. Journal of Garmian University. Conference Paper. 301319. Doi: 10.24271/garmian.144. (2017)

21. Radke, J., Andra, S., Al-Kofani, O., Roysan, B. (2005). Image change detection algorithms: a systematic survey," IEEE Trans. Image Process, V.14 (3). PP.291307.Doi: (2005)

22. Pilon, G., Howarth, J., Bullock, A. "An enhanced classification approach to change detection in semi-arid environments," Photogrammtry Engineering and Remote Sensing, V.54, pp. 1709-1716.Doi: 0099-1112/88/5412-1709\$02.25/0 (1988)

23. El-Baz, F., Breed, C., Grolier, J., McUauley, J. Eolian features in the western desert of Egypt and some applications to Mars. Journal of Geophysical Research Atmosphere. Res. V.84. pp.8205-8221.Doi: https://doi.org/10.1029/JB084iB14p08205 (1979)

24. Ibrahim, A. L., \&Sarvestani, M. S. Urban Sprawl Pattern Recognition Using Remote Sensing and GIS - Case Study Shiraz City, Iran, Urban Remote Sensing Joint Event. IEEE Joint Urban Remote Sensing Event, 1-6. Doi: https://doi.org/10.1109/URS.2009.5137528 (2009)

25. Abdul Razzak T. Ziboon, Imzahim Abdulkareem Alwan, Alaa Ghadhban Khalaf,.Utilization of Remote Sensing Data and GIS Applications for Determination of the Land Cover Change in Karbala Governorate. Engineering and Technology Journal, Volume 31, Issue 15 Part (A) Engineering, Pages 2773-2787. Doi: https://etj.uotechnology.edu.iq/article_83264.html(2013)

26. Hadeal H. Alzamili1, Mahmoud El-Mewafi, Ashraf M. Beshr. Monitoring urban growth andland use change detection with GIS and remote sensing techniques in AlNasiriyah city in Iraq. International Journal of Scientific \& Engineering Research, Volume 6, Issue 7, 1330-1335.Doi: (2015)

27. Faqe Ibrahim GR. Urban Land Use Land Cover Changes and Their Effect on Land surface Temperature: Case Study Using Dohuk City in the Kurdistan Region of Iraq. Climate; 5(1):13. https://doi.org/10.3390/cli5010013(2017)

28. Khwarahm, Nabaz, Qader, Sarchil, Ararat, Korsh and Fadhil Al-Quraishi, Ayad. Predicting and mapping land cover/land use changes in Erbil /Iraq using CAMarkov synergy model.Earth Science Informatics. Volume 14. 393-406. Doi: doi:10.1007/s12145-020-00541-x (2021)

29. Shalaby, A., Tateishi, R. Remote sensing and GIS for mapping and monitoring landcover and land-use changes in the Northwestern coastal zone of Egypt," Applied Geography. 27, 28-41. Doi: dx.doi.org/10.1016/j.apgeog.2006.09.004 (2007)

30. allmapsoft.com, Online database to provide areal and satellite images, [online]. Available: www.allmapsoft.com/

31. Sidhu, N., E. Pebesma, and G. Câmara. Using Google Earth Engine to Detect Land Cover Change: Singapore as a Use Case. European Journal of Remote Sensing V.51, pp.486-500.Doi: https://doi.org/10.1080/22797254.2018.1451782(2018)

32. Fabio Pacifici, Marco Chini, William J. Emery, A neural network approach using multi-scale textural metrics from very high-resolution panchromatic imagery for urban land-use classification, Remote Sensing of Environment, V. 113, Issue 6, pp 12761292.Doi: http://dx.doi.org/10.1016/j.rse.2009.02.014(2009)

33. Celik, N. Change detection of urban areas in Ankara through Google Earth engine. In Proceedings of the 2018 41st International Conference on Telecommunications and Signal Processing (TSP), Athens, Greece, pp. 1-5. Doi: http://dx.doi.org/10.1109/TSP.2018.8441377 (2018)

34. Iraqi Economic Network,September 14, 2019.[online]. Available: http://iraqieconomists.net/

35. Statistical Survey on Offices in Sulaimanya \& Garmain Governorate, Slemani Directorate of Statistics website, [online]. Available: www.sulamar.com 